This document is the Accepted Manuscript version of a Published Work that appeared in final form in Analytical Chemistry, copyright (c) American Chemical Society after peer review and technical editing by the publisher. To access the final edited and published work, see http://pubs.acs.org/doi/abs/10.1021/acs.analchem.5b00923 (DOI: 10.1021/acs.analchem.5b00923) 
This is the Accepted Manuscript version of a Published Work appeared in:

Analytical Chemistry, 2015, Volume 87, Pages 6233-6239

(DOI: 10.1021/acs.analchem.5b00923)

\title{
Development of a novel bidimensional spectroelectrochemistry cell using transfer single walled carbon nanotubes films as optically transparent electrodes
}

\author{
Jesus Garoz-Ruiz, Aranzazu Heras, Susana Palmero, Alvaro Colina* \\ Department of Chemistry, Universidad de Burgos, Pza. Misael Bañuelos s/n, E-09001, Burgos, Spain
}

\begin{abstract}
A really easy method to transfer commercial single-walled carbon nanotubes (SWCNTs) to different substrates is proposed. In this paper, a homogeneous transference of SWCNTs films to non-conductor and transparent supports such as polyethylene terephthalate, glass and quartz, and to conductor supports such as indium tin oxide, aluminium, highly ordered pyrolytic graphite and glassy carbon was achieved using a very fast, reproducible and clean methodology. In order to test these transferences, SWCNTs films transferred on quartz were used as working optically UV-Vis transparent electrodes due to their optimal electrical and optical properties. A new easy-to-use, homemade optical fiber based cell for bidimensional spectroelectrochemistry was developed, offering the possibility to measure in normal and parallel configuration. The cell was tested with ferrocenemethanol, a compound widely used in electrochemistry but scarcely studied by spectroelectrochemistry, covering the UV-Vis spectral region.
\end{abstract}

Bidimensional spectroelectrochemistry ${ }^{1}$ (BSEC) is a powerful multi-response technique that offers the possibility of obtaining simultaneously one electrochemical and two spectroscopic signals providing independent but complementary information. A parallel light beam passes through the solution layer adjacent to the electrode surface, while, at the same time, another light beam samples the system in perpendicular direction to the electrode surface. In this way, information related to the processes that take place in the solution and on the electrode surface is obtained together with the electrochemical response in a single experiment.

BSEC has emerged as a very useful technique to understand complex electrochemical reactions, ${ }^{2}$ providing time-resolved information about the different products generated during the electrode processes. This multi-response technique has been applied in the study of diffusive processes and adsorptive electrode reactions, including electrogeneration of soluble Prussian Blue from hexacyanoferrate(II) solutions, ${ }^{3}$ and organic conducting polymers such as polyaniline, ${ }^{4}$ poly $(3,4-$ ethylenedioxythiophene) and polybithiophenes. ${ }^{1,2,6-8}$ Spectroelectrochemistry in general and BSEC in particular provide inherent and competitive advantages that have allowed us to obtain, for example, valuable information related to both the polymer and the soluble oligomers electrogenerated during an electropolymerization ${ }^{6,8}$ and to side-reactions during an electrochemical reaction. ${ }^{9}$
Although a few mono-dimensional spectroelectrochemistry cells and instruments are commercially available, to the best of our knowledge there are neither BSEC cells nor BSEC instruments probably due to the technical complexity of this technique. By this reason, a new BSEC cell based on optical fibers is presented in this paper. The new cell is particularly simple in both the assembly of all parts and the alignment of the light beams, allowing to measure in both normal and parallel configuration in the UV-Vis spectral region.

As is known, optically transparent electrodes (OTEs) are needed to work in normal transmission spectroelectrochemistry, being necessary a good transparency to ensure that the normal light beam passes across the electrode, and a good electrical conductivity to obtain information about the electron transfer. In this sense, carbon nanotubes (CNTs) are one of the most promising carbon nanomaterials. ${ }^{10}$ Their optical and electrical properties have made them potential targets for nanotechnology and their use in analytical chemistry, ${ }^{11}$ specifically in electroanalysis, ${ }^{12}$ is undoubtedly outstanding, especially due to their catalytic properties. ${ }^{13,14}$ They are relatively easy to modify or functionalize $e^{15,16}$ to improve their properties and expand their scope of applications. Meanwhile, homogeneous thin films of CNTs are required for several applications, ${ }^{17}$ highlighting sensors ${ }^{18}$ and OTEs. ${ }^{19-23}$

The transference of CNTs films to a variety of supports is of great importance. This transference step is commonly carried 
out with chemical vapor deposition (CVD) films ${ }^{24,25}$ using different methods including dry-transfer, ${ }^{26}$ imprinted conductive adhesive, ${ }^{27}$ functionalization of $\mathrm{CNTs},{ }^{28}$ transfer printing, ${ }^{29}$ contact printing, ${ }^{30}$ stacked multiple transfer, ${ }^{31}$ spin coating of a polymethylmethacrylate film, ${ }^{32}$ using the growth substrate as a stamp, ${ }^{33}$ one-step direct transfer, ${ }^{34}$ laser assisted, ${ }^{35}$ or using polydimethylsiloxane. ${ }^{36}$ Growing CNTs onto a catalyst and subsequent sputtering ${ }^{37}$ and spray deposition ${ }^{38}$ are other ways that yield good results. However, some of these techniques are not available for all laboratories.

Filtering CNTs dispersions is another methodology that also gets good results. ${ }^{39-43}$ Nevertheless, the use of strong etching agents such as nitric acid, the need to dissolve the filter or the use of surfactants to obtain good CNTs dispersions introduce unnecessary impurities that can affect the optical and electrical behavior of CNTs. There are also some supports that cannot resist the pressure, the vacuum or the curing processes required by some methods cited above. Besides, a large number of intermediate steps are associated to difficult and tedious transferences.

Herein, we propose a new methodology that removes some previous disadvantages and allows us the transference of commercial single-walled carbon nanotubes (SWCNTs) to many different supports using a standard, inexpensive and clean methodology. In a previous work, we have optimized the experimental conditions to fabricate SWCNTs electrodes using a press-transfer methodology, achieving good transmittance and conductivity values. ${ }^{19}$ These SWCNTs electrodes have been successfully used for the quantitative determination of catechol and dopamine by spectroelectrochemistry ${ }^{44}$ and electrochemical microfluidic sensing. ${ }^{45}$ In this work, we have simplified the process avoiding the high pressure step and facilitating the transference process to almost any support.

Ferrocenemethanol $(\mathrm{FcMeOH})$ is an electroactive compound that shows a simple, well-defined, one-electron chemically reversible electrochemical process. By these reasons, it has been commonly used as a redox probe in aqueous solution. Recently, FcMeOH has also been utilized to modify CNTs electrodes in the field of molecular memory ${ }^{46}$ and as a mediator to improve electron transfer, for example, in detection assays of glucose, ${ }^{47,48}$ ascorbic acid ${ }^{49}$ and lipid hydroperoxides, ${ }^{50}$ and to explore $\mathrm{Ag}^{+}$toxicity on single living fibroblast cells. $^{51}$

However, FcMeOH has been scarcely studied by spectroelectrochemistry ${ }^{52,53}$ and never by BSEC. This redox couple can be used as a probe not only in electrochemistry, but also in spectroelectrochemistry. Here, $\mathrm{FcMeOH}$ is studied and characterized using a SWCNTs-OTE fabricated on an UV-Vis transparent support, establishing the differences between the signals obtained in normal transmission and parallel configuration using BSEC. Spectral evolution during FcMeOH electron transfer process is used to validate both our pressureless transfer SWCNTs-OTEs prepared on quartz and the performance of the new BSEC device.

\section{EXPERIMENTAL SECTION}

Reagents and materials: SWCNTs (Sigma-Aldrich), 1,2dichloroethane (DCE, 99.8\% for HPLC, Acros Organics), nitrocellulose membrane (filter pore size $0.8 \mu \mathrm{m}$, Millipore), quartz (Sugelabor), silver conductive paint (Electrolube), and nail polish (Procesos Cosméticos) were used to fabricate the
SWCNTs-OTEs. FcMeOH (97\%, Sigma-Aldrich) and $\mathrm{KCl}$ (Acros Organics) were used to prepare the solutions. Poly(ethylene terephthalate) (PET), glassy carbon (GC), aluminium foil, highly ordered pyrolytic graphite (HOPG), glass and indium tin oxide (ITO) were the supports used to transfer the SWCNTs films. Poly(methyl methacrylate) (PMMA), nuts and bolts were the material to fabricate the cell.

All the reagents were used as received without further purification. All chemicals were analytical grade. Aqueous solutions were prepared freshly using high purity water (18.2 $\mathrm{M} \Omega \cdot \mathrm{cm}$ resistivity at $25^{\circ} \mathrm{C}$, Milli-Q A10 system, Millipore).

Instrumentation: BSEC set-up includes a potentiostat/galvanostat (PGSTAT302N, Metrohm Autolab), a halogen-deuterium light source (AvaLight-DH-S-BAL, Avantes), a bifurcated optical fiber $(600 \mu \mathrm{m}$, Ocean Optics), bare optical fibers (100 $\mu \mathrm{m}$, Ocean Optics), a collimating lens, an optical fiber probe $(200 \mu \mathrm{m}$, Avantes $)$ and two spectrometers (QE65000 198-1006 $\mathrm{nm}$ for parallel configuration and QE65000 250-1045 $\mathrm{nm}$ for normal transmission configuration, both from Ocean Optics). A tip-sonicator (CY-500, Optic ivymen System) was also used to disperse properly the SWCNTs in DCE. Field emission scanning electron microscopy (FE-SEM) images were recorded on a Zeiss SUPRA 55-VP microscope.

Safety considerations: All handling and processing were performed carefully, particularly when DCE was used. SWCNTs dispersions were stored in tempered glass material, nitrogen flushed and film coated.

SWCNTs film preparation and transfer: The need to transfer commercial CNTs onto different types of supports in a homogeneous, reproducible, versatile, quick and inexpensive way makes this step very important. Our new methodology is capable of transferring SWCNTs to many different supports, including conducting/insulating, polymeric/metal/carbon, opaque/transparent, flexible/rigid and resistant/fragile supports. In this work, the transfers of SWCNTs films have been successfully made to pieces of PET, glass, quartz, ITO, aluminium, HOPG and GC of different shapes and sizes.

Our methodology begins with the preparation of a dispersion of $0.5 \mathrm{mg}$ of SWCNTs in $100 \mathrm{~mL}$ of DCE $(5 \mathrm{mg} / \mathrm{L})$. SWCNTs dispersion was performed in three sonication steps: 1) $0.5 \mathrm{mg}$ of SWCNTs were weighed and $10 \mathrm{~mL}$ of DCE were added and it was sonicated at $250 \mathrm{~W}$ for 15 minutes, 2) DCE was added to obtain a dispersion volume of $c a .90 \mathrm{~mL}$ which was sonicated at $100 \mathrm{~W}$ for 20 minutes more, and 3) the dispersion was sonicated more vigorously at $250 \mathrm{~W}$ for another $20 \mathrm{~min}$. Finally, the volume was adjusted to $100 \mathrm{~mL}$. To ensure always a good homogeneity in this dispersion, avoiding SWCNTs agglomeration, $10 \mathrm{~mL}$ of the dispersion were sonicated for $3 \mathrm{~min}$ at $100 \mathrm{~W}$ before preparing the transfers. Then, the desired volume, in this case $0.8 \mathrm{~mL}$, was filtered under vacuum through the nitrocellulose filter, where the SWCNTs formed a homogeneous film whose transparency and conductivity depend on the filtered volume of the SWCNTs dispersion. ${ }^{19}$ Immediately afterwards, without letting the SWCNTs and the filter dry (this is the key point to transfer the SWCNTs film at very low pressure), the filter was placed on the chosen support with the SWCNTs film in front of it. The back face of the filter was covered with a PET sheet which was slightly pressed just with fingers for no more than $10 \mathrm{~s}$. Finally, the PET sheet was removed and the filter was dried at room temperature for $5 \mathrm{~min}$. Transfer process was completed when the 
filter was gently separated from the support using tweezers. Homogeneous and circular SWCNTs films of $10 \mathrm{~mm}$ in diameter were obtained. Homogeneity and transparency of the transferences to different supports are clearly evident in Figure S1 (see Supporting Information, SI).

Several new features and advantages of this methodology can be highlighted when compared to other cited above. A hydraulic press is not needed, which expands greatly the possibility of transferring the SWCNTs film to almost any support, particularly fragile supports such as quartz or glass and supports that deform under pressure. Furthermore, SWCNTs are dispersed in DCE without surfactants and chemicals are not used to remove the filter from the SWCNTs film. Therefore, very clean, homogeneous and reproducible films are obtained using this methodology.

As a proof of concept, quartz was chosen as support to fabricate the SWCNTs-OTEs due to its transparency in the UVVis region. Moreover, quartz is a rigid and fragile material that breaks under pressure. Thus, our previous press-transfer meth$\operatorname{odology}^{19}$ is not useful to transfer the film. Two FE-SEM images of a SWCNTs film transferred on a quartz support using the new methodology are shown in Figure 1.

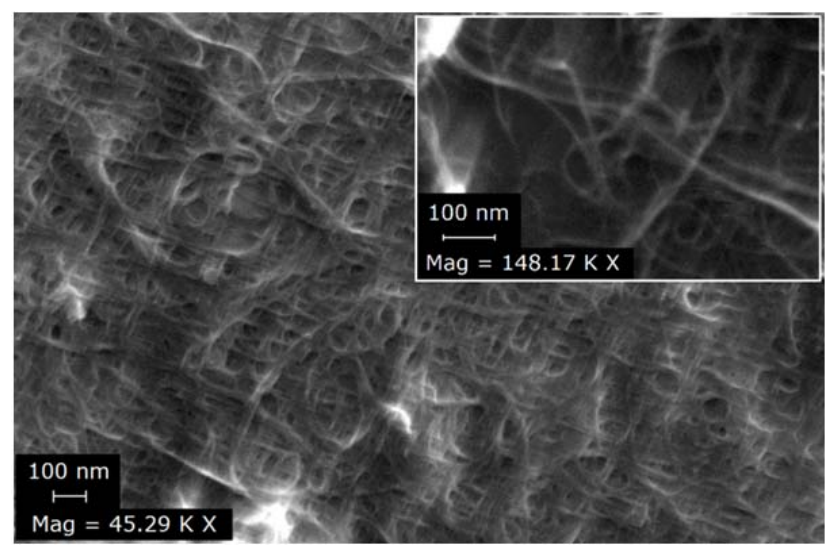

Figure 1. FE-SEM image of a $0.8 \mathrm{~mL}$ SWCNTs film transferred on quartz. Inset: Higher magnification FE-SEM image to observe SWCNTs in detail.

Electrode fabrication: Once the SWCNTs film was transferred on the support, the electrical contact was made with silver conductive paint from the SWCNTs film to the edge of the quartz. It was dried in an oven at $75^{\circ} \mathrm{C}$ for $45 \mathrm{~min}$. After cooling, silver was electrically isolated using transparent nail polish, which was also dried at room temperature, ensuring a good covering and resistance to aqueous solutions. Other insulators can be used depending on the application of the electrode. The SWCNTs-OTE thus fabricated by filtering 0.8 $\mathrm{mL}$ of the SWCNTs dispersion had a transmittance around $60 \%$ at $550 \mathrm{~nm}$, in agreement with the results obtained previously for press-transfer SWCNTs-OTEs. ${ }^{19}$

Design and fabrication of the optical fiber BSEC cell: A photograph, a schematic view of the disassembled cell and a detailed schematic view of the experimental set-up are shown in Figure 2.The BSEC cell was fabricated in PMMA by using a high precision $\mathrm{CO}_{2}$ laser cutting machine. The cell consists of three different PMMA pieces with holes in the corners to set them with nuts and bolts in a reproducible way. The lateral dimensions are $5 \times 3.5 \mathrm{~cm}$, and the height when the BSEC cell is assembled is $1.6 \mathrm{~cm}$. The bottom piece of the cell $(1$ in Figure $2 b$ ) has a cylindrical hole, drilled in its center, to place a collimating lens where the optical fiber from the light source is connected for normal transmission configuration measurements. The middle piece ( 2 in Figure $2 b$ ) has a rectangular space to introduce the electrode. Eleven micro-channels were done at each part of the rectangular space to accurately align the optical fiber from the light source with the optical fiber to the spectrometer in parallel arrangement. These microchannels ensure the correct alignment of the optical fibers at any optical path length, offering the opportunity to study spectroscopically the electron transfer at different locations of the electrode surface area. The light beam in parallel configuration passes parallel and close to the electrode surface, sampling only the solution adjacent to the electrode. In the experiments shown in this work the parallel light beam is collected by a $100 \mu \mathrm{m}$ bare optical fiber placed a known distance away from a $100 \mu \mathrm{m}$ light emitting bare optical fiber. A great advantage of this experimental set-up is the fact that the optical fibers diameter and the distance between the fibers can be easily changed. Finally, the upper piece ( 3 in Figure $2 b$ ) has a rectangular hole to introduce the solution, the reference and counter electrodes, and the optical fiber probe to collect the light beam that passes through the OTE and the solution in normal configuration and it is conducted to the second spectrometer.
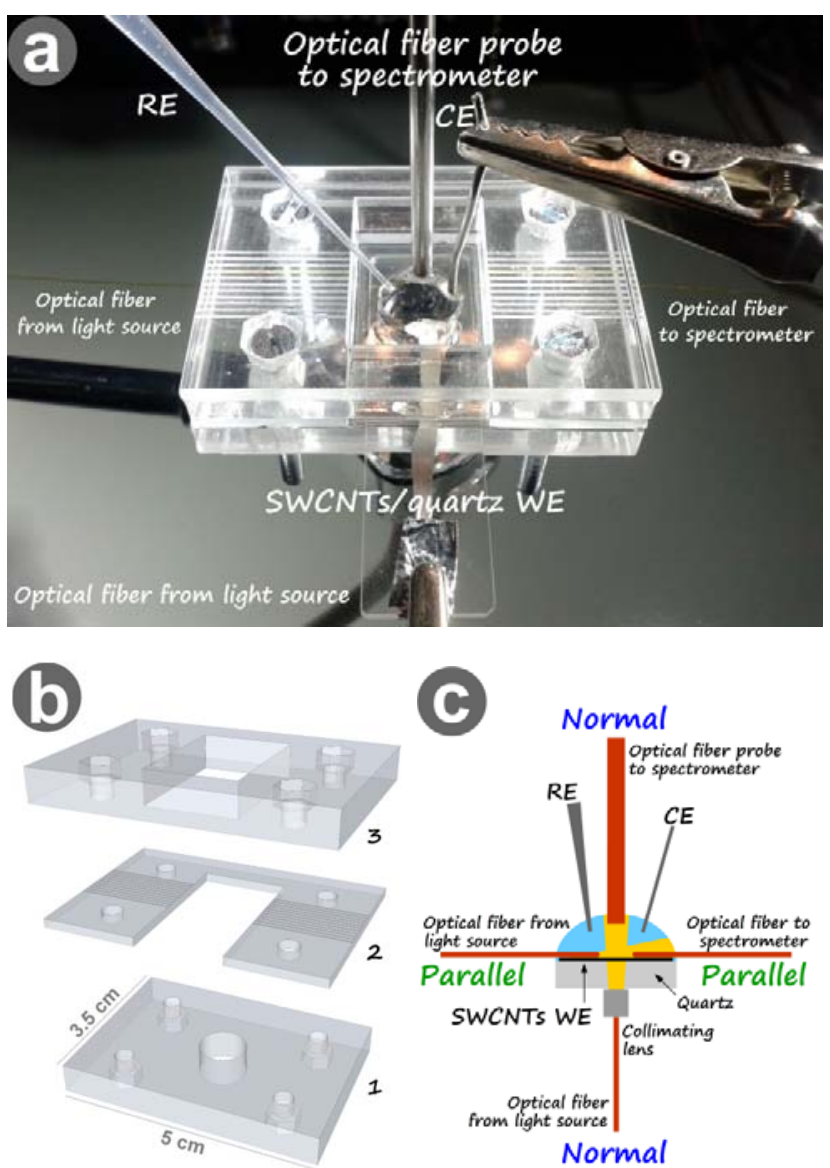

Figure 2. (a) Photograph of the assembled cell ready to measure, (b) schematic view of the disassembled cell, and (c) detailed schematic view of the experimental set-up. 
The homemade BSEC cell described here has a simple assembling and is very easy-to-use. It was optimized to be utilized in normal transmission and parallel configurations in semi-infinite diffusion regime. Little changes in the arrangement of some elements would allow us to work in parallel and normal reflection configuration or in thin-layer diffusion regime.

Experimental set-up for BSEC measurements: The light beam from the halogen-deuterium source was conducted by a $600 \mu \mathrm{m}$ bifurcated optical fiber to the BSEC cell, allowing the light to pass through the solution adjacent to the electrode surface in parallel configuration and, simultaneously, to pass through the OTE and the solution in normal transmission configuration.

In parallel arrangement, the bifurcated optical fiber was coupled with a $100 \mu \mathrm{m}$ bare optical fiber that was placed in one of the eleven micro-channels of the cell touching partially the electrode surface. Another $100 \mu \mathrm{m}$ bare optical fiber was placed in the corresponding micro-channel, just in front of the previous one, touching also the electrode surface. This second optical fiber was used to collect the light beam after sampling the solution close to the electrode and it was directly conducted to the spectrometer.

In normal transmission configuration, a lens collimated the light beam from the bifurcated $600 \mu \mathrm{m}$ optical fiber to the electrode allowing the light to pass through the solution and the OTE. The transmitted light was collected by a $200 \mu \mathrm{m}$ optical fiber probe and it was conducted to the other spectrometer.

The optical path length in parallel configuration is the distance between the two $100 \mu \mathrm{m}$ bare optical fibers, which was $2.1 \mathrm{~mm}$, while the separation between the optical fiber probe and the electrode surface was $c a .1 .5 \mathrm{~mm}$.

In all experiments, $150 \mathrm{~ms}$ was selected as integration time for the spectra acquisition in parallel configuration and $50 \mathrm{~ms}$ in normal arrangement. A $100 \mu \mathrm{L}$ solution drop was placed on the working electrode surface, covering the end of the optical fibers for parallel measurements and the optical fiber probe for normal configuration. Finally, a homemade $\mathrm{Ag} / \mathrm{AgCl} / \mathrm{KCl} 3 \mathrm{M}$ reference electrode (RE) and a platinum wire counter electrode (CE) were immersed in the solution drop.

\section{RESULTS AND DISCUSSION}

$\mathrm{FcMeOH}$, as other ferrocene derivatives, is a compound widely used in electrochemistry. We have selected this redox couple to evaluate the performance of the SWCNTs-OTEs, to validate the proposed cell and to characterize this compound that has been scarcely used in spectroelectrochemistry.

Figure 3 shows 3D plots of the spectra evolution with time/potential in normal transmission and parallel configuration recorded during a cyclic voltammetry of $5 \cdot 10^{-4} \mathrm{M}$ FcMeOH in $0.1 \mathrm{M} \mathrm{KCl}$ between $-0.20 \mathrm{~V}$ and $+0.60 \mathrm{~V}$ at 0.005 $\mathrm{V} \cdot \mathrm{s}^{-1}$, demonstrating the good behavior of the system.

Several implicit similarities and differences can be found when normal transmission and parallel configuration plots are compared. The electrochemical reaction generates a concentration gradient that can be easily studied using our BSEC cell. Absorbance values for parallel configuration $\left(A_{P}\right)$ are higher than normal absorbance values $\left(\mathrm{A}_{\mathrm{N}}\right)$, due to the longer optical path length. In general, this is one of the main advantages of long optical path cells because they show a higher sensibility and, therefore, a lower limit of detection. Spectra at the vertex potential, $+0.60 \mathrm{~V}$, are plotted in the insets of Figure 3, exhibiting two sharp absorption bands at 260 and $282 \mathrm{~nm}$ and a smaller one at around $630 \mathrm{~nm}$. An enlarged view of this small band is plotted in the SI (Figures S2a and S2b). The reduced form of the redox couple, $\mathrm{FcMeOH}$, was taken as reference spectrum of the experiment and there were no other absorbent compounds in solution. Taken this into account and knowing that the studied reaction follows a simple reversible diffusion regime, these new bands are attributed to the oxidized form of $\mathrm{FcMeOH} \mathrm{FcMeOH}^{+}$.

Several cyclic voltammetries at different scan rates between 0.005 and $0.08 \mathrm{~V} \cdot \mathrm{s}^{-1}$ were performed under the same experimental conditions, for which $\mathrm{FcMeOH}$ solution was changed after every measurement. A blank experiment in $0.1 \mathrm{M} \mathrm{KCl}$ at $0.01 \mathrm{~V} \cdot \mathrm{s}^{-1}$ was also performed at the end of all the measurements, demonstrating that there is no change of absorbance with potential in this case.
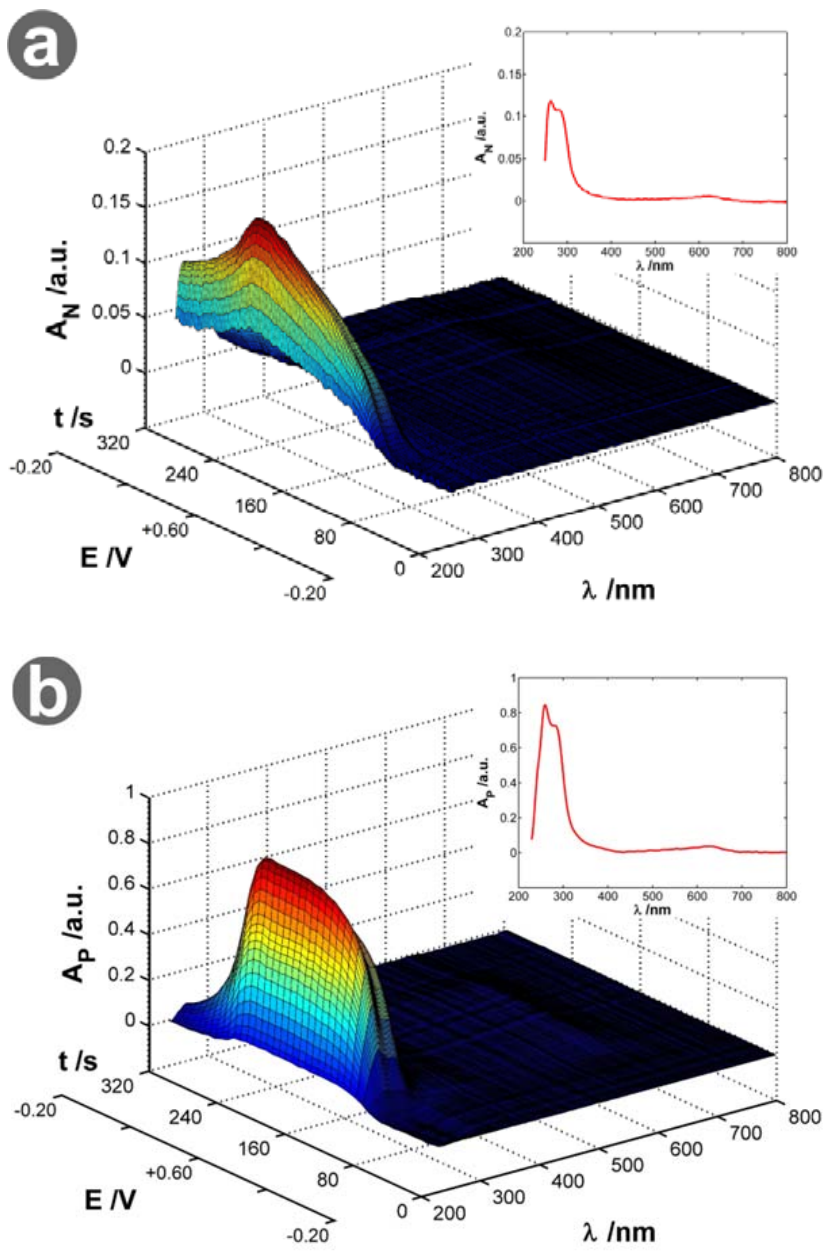

Figure 3. Spectra evolution with time/potential in normal transmission (a) and parallel (b) configuration recorded during a cyclic voltammetry of $5 \cdot 10^{-4} \mathrm{M} \mathrm{FcMeOH}$ in $0.1 \mathrm{M} \mathrm{KCl}$ between $0.20 \mathrm{~V}$ and $+0.60 \mathrm{~V}$ at $0.005 \mathrm{~V} \cdot \mathrm{s}^{-1}$. Insets: spectra at $+0.60 \mathrm{~V}$ for the oxidized form of $\mathrm{FcMeOH}, \mathrm{FcMeOH}^{+}$.

Figure 4 shows the evolution of the charge (Figure 4a) and the absorbance at $282 \mathrm{~nm}$ in normal transmission (Figure $4 \mathrm{~b}$ ) and parallel (Figure 4c) configuration with potential for all the 
cyclic voltammetry experiments. Cyclic voltammograms and the derivative voltabsorptograms at $282 \mathrm{~nm}$ in normal and parallel configuration corresponding to the experiment shown in Figure 4 can be found in the SI (Figures S3, S4a and S4b, respectively).

As can be observed in Figure 4, charge and $\mathrm{A}_{\mathrm{N}}$ show a similar behavior but $A_{P}$ response shows a different shape. Absorbance in parallel arrangement is always higher than absorbance in normal configuration. For the three responses, it is observed that charge and absorbance values begin to increase around $+0.20 \mathrm{~V}$ in the forward scan, where $\mathrm{FcMeOH}$ starts to be oxidized, until the vertex potential at $+0.60 \mathrm{~V}$. During the backward scan, differences between the optical signal in normal and parallel configuration are more evident. While charge and $\mathrm{A}_{\mathrm{N}}$ increase at the beginning of the backward scan for the five scan rates, $A_{P}$ does not increase for the lowest one $(0.005$ $\left.\mathrm{V} \cdot \mathrm{s}^{-1}\right)$, reaching a constant value of 0.79 a.u. due to the steadystate achieved in the first $100 \mu \mathrm{m}$ sampled by the parallel optical fibers. On the contrary, in the other four experiments at higher scan rates, parallel absorbance increases during the first part of the backward scan because there has been no time to reach a steady-state.

It is also noteworthy that the final values of both $A_{N}$ and charge decrease with the scan rate. On the contrary, final $A_{P}$ value increases with the scan rate. These differences can be explained taking into account the solution sampled by the light beams. Although the three responses are related to concentration changes taking place in the diffusion layer, the optical information in parallel arrangement depends only on the nearest solution region to the electrode surface, containing information about the diffusion of the species, ${ }^{54}$ their spatial distribution according to the optical fiber diameter $(100 \mu \mathrm{m}$ in our case) and its position with respect to the electrode surface. Meanwhile, $\mathrm{A}_{\mathrm{N}}$ and charge include information related to the global amount of $\mathrm{FcMeOH}$ that is oxidized to $\mathrm{FcMeOH}^{+}$and that diffuses away from the diffusion layer.

As can be seen in Figure S4a, derivative voltabsorptograms at $282 \mathrm{~nm}$ in normal transmission configuration show features comparable to the cyclic voltammograms (Figure S3). On the contrary, very contrasting behavior is observed from the corresponding voltabsorptograms in parallel configuration (Figure S4b) because of the influence of the spatial distribution of $\mathrm{FcMeOH}^{+}$respect to the optical fibers. Particularly, the $20 \mu \mathrm{m}$ solution closest to the electrode surface cannot be sampled by the parallel light beam due to the cladding material of the optical fibers. In this way, at the higher scan rates, the cladding material provokes a clear change in the optical response. However, at low scan rates this fact does not affect to the optical response since the diffusion layer is much bigger.

Thus, $0.005 \mathrm{~V} \cdot \mathrm{s}^{-1}$ is a low enough scan rate to generate an almost homogeneous steady-state distribution of $\mathrm{FcMeOH}^{+}$in the sampled solution in parallel arrangement. In this case, a constant and maximum value of $A_{P}$ is achieved because the optical fiber only samples the first $100 \mu \mathrm{m}$ of the solution adjacent to the electrode surface. $\mathrm{FcMeOH}^{+}$diffuses far away from the first $100 \mu \mathrm{m}$ to the bulk solution explaining the behavior of charge and $\mathrm{A}_{\mathrm{N}}$. The generation of $\mathrm{FcMeOH}^{+}$takes place at potentials over $+0.20 \mathrm{~V}$, growing the diffusion layer and increasing the values of these three signals until the potential is low enough to reduce the $\mathrm{FcMeOH}^{+}$. $\mathrm{FcMeOH}^{+}$consumption rate on the electrode surface during the reduction step is faster than the diffusion rate of this cation in solution.
Thus, a fraction of the electrogenerated $\mathrm{FcMeOH}^{+}$remains always in solution and, therefore, $A_{P}$ decreases faster than $A_{N}$. Most part of the $\mathrm{FcMeOH}^{+}$that is present in the sampled solution in parallel arrangement can be reduced because it is close to the electrode surface, resulting in a faster decrease of $A_{P}$ than $A_{N}$, being $A_{N}$ related to the whole diffusion layer.

The amount of $\mathrm{FcMeOH}^{+}$generated is lower when the scan rate is increased. In this case, the cation diffuses a shorter distance respect to the electrode surface and then, a more heterogeneous distribution of $\mathrm{FcMeOH}^{+}$on the $100 \mu \mathrm{m}$ adjacent to the electrode surface is observed. Accordingly, at higher scan rates, the $A_{P}$ voltabsorptograms (Figure 4c) are more similar to both the charge and the $A_{N}$ voltabsorptograms because almost the whole diffusion layer is sampled in parallel configuration.

Linear regressions of $A_{N} v s$. $Q$ for the experiments at the different scan rates were performed. From the slopes, and being $n=1, F=96485 \mathrm{C} \cdot \mathrm{mol}^{-1}$ and $S=0.63 \mathrm{~cm}^{2}$, the difference of the molar absorption coefficients of $\mathrm{FcMeOH}^{+}\left(\varepsilon_{F c}^{+}\right)$and FcMeOH $\left(\varepsilon_{F c}\right)$ can be obtained at any wavelength of the UVVis spectral region using the equation 1 (see details in SI, Section S5):

$$
A_{N}=\left(\varepsilon_{F c^{+}}-\varepsilon_{F c}\right) \frac{10^{3}}{n F S} Q
$$
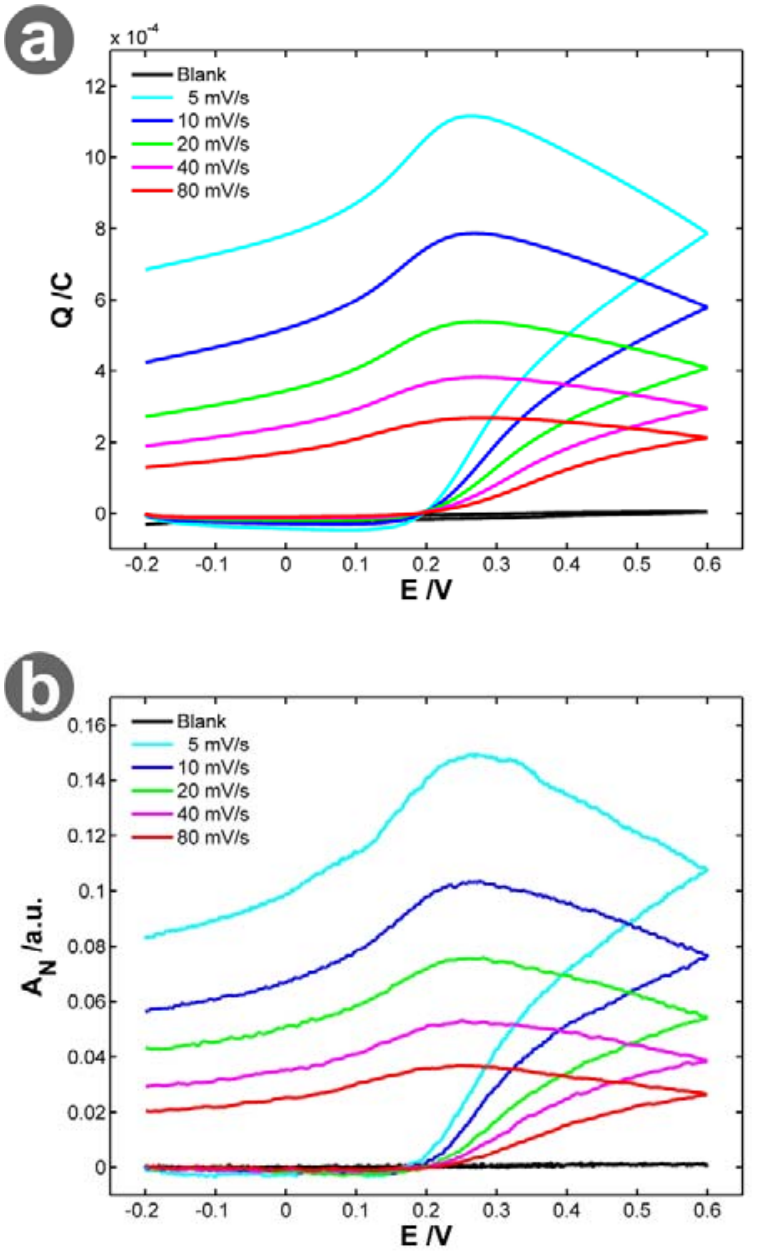


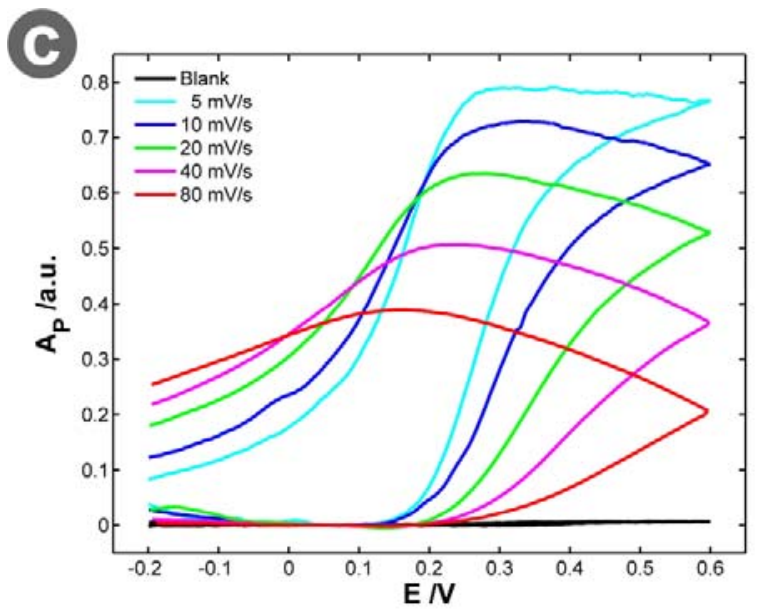

Figure 4. (a) Evolution of charge vs. potential, (b) voltabsorptogram at $282 \mathrm{~nm}$ in normal configuration, and (c) voltabsorptogram at $282 \mathrm{~nm}$ in parallel configuration, at different potential scan rates. Experimental conditions as in Figure 3.

In order to check the good performance of the new BSEC cell, the molar absorption coefficient of $\mathrm{FcMeOH}^{+}$at $282 \mathrm{~nm}$ has been assessed. The experimental value for the difference of $\varepsilon_{F c}{ }^{+}$and $\varepsilon_{F c}$ from the five slopes was $7880 \pm 510 \mathrm{M}^{-1} \cdot \mathrm{cm}^{-1}$. The molar absorption coefficient at $282 \mathrm{~nm}$ for $\mathrm{FcMeOH}, \varepsilon_{F c}$, obtained by calibration using our spectrometer, was $930 \pm 20$ $\mathrm{M}^{-1} \cdot \mathrm{cm}^{-1}$. This value must be added to the previous difference to obtain the corresponding molar absorption coefficient for $\mathrm{FcMeOH}^{+}$which is $8810 \pm 530 \mathrm{M}^{-1} \cdot \mathrm{cm}^{-1}$.

We used the difference of the molar absorption coefficients to calculate the $A_{P}$ estimated value, using the Beer-Lambert law and assuming that a $\mathrm{FcMeOH}$ concentration of $5 \cdot 10^{-4} \mathrm{M}$ has been transformed to $\mathrm{FcMeOH}^{+}$in the $100 \mu \mathrm{m}$ closest to the electrode surface. From our optical path length of $2.1 \mathrm{~mm}$ in parallel configuration, a value of $A_{P}$ of $0.83 \pm 0.05$ a.u. is obtained at $282 \mathrm{~nm}$. This result agrees with the experimental value of 0.79 a.u. obtained for the steady-state reached in the parallel voltabsorptogram corresponding with the experiment performed at the lowest scan rate, $0.005 \mathrm{~V} \cdot \mathrm{s}^{-1}$, in which all the assumptions are fulfilled (Figure $4 c$ ). In fact, the $A_{P}$ estimated value should be, and is a little bit higher than the $A_{P}$ theoretical value and therefore, than the experimental one due to the heterogeneity in the concentration profile. But, for low scan rates and small diameter optical fibers, $A_{P}$ estimated and theoretical values are very close. The good agreement between the $A_{P}$ estimated and experimental values indicates the good performance of our novel BSEC cell and corroborates the trueness of the molar absorption coefficients assessed.

A chronoabsorptometry was performed to provoke an exhaustive electrolysis in the solution sampled by the optical fiber. Figure S6 shows the absorbance at $282 \mathrm{~nm} v s . t^{1 / 2}$ graph in the two configurations. Absorbance in normal configuration shows a linear behavior, as is expected for a Cottrell response. Meanwhile, absorbance in parallel configuration does not change initially because of the cladding material but an exhaustive electrolysis in the first $100 \mu \mathrm{m}$ next to the electrode surface takes place in less than $120 \mathrm{~s}$.

These results demonstrate that the SWCNTs-OTEs fabricated are very useful for BSEC measurements in the UV-Vis spectral region. Besides, the reduced size of the developed
BSEC cell $(5 \times 3.5 \times 1.6 \mathrm{~cm})$, the small volume of sample, the high versatility related to materials, shapes and sizes of electrodes, the wide spectral region covered, the possibility of fixing simultaneously several optical fibers in parallel arrangement at any optical path length and at different positions respect to the electrode surface and the possibility of combining different configurations (parallel configuration with normal transmission and/or reflection arrangement) are some important advantages of this easy-to-use BSEC cell. This is definitely a novel, simple, useful and original option to work with BSEC. The novel experimental set-up has been verified with the good results obtained with $\mathrm{FcMeOH}$ and the SWCNTs-OTEs, demonstrating the good performance of this BSEC cell to obtain qualitative and quantitative information. Moreover, this methodology is very useful to obtain the molar absorption coefficient value of substances at any wavelength of the UV-Vis spectrum. This value can be checked in parallel configuration when a steady-state is reached in the proximity of the electrode, which takes place at slow enough scan rates. Therefore, BSEC is also very useful to obtain and validate the molar absorption coefficient assessed with $\mathrm{A}_{\mathrm{N}}$ by comparison with the expected $A_{P}$ value.

\section{CONCLUSIONS AND FUTURE WORK}

A new simple methodology based on filtering a dispersion of SWCNTs has allowed us to transfer commercial SWCNTs onto a variety of supports in an available way for any laboratory. A good homogeneity, transparency and conductivity were obtained in a quick, inexpensive, reproducible and clean process, without surfactants, strong etching agents, pressure or heat. SWCNTs transferred on quartz supports have been used as OTEs for BSEC, demonstrating the good performance of this type of electrodes for spectroelectrochemistry. A new optical fiber BSEC cell with an easy assembly, a very simple light beam alignment, a reduced size and a purposely built low-volume has been fabricated. BSEC was a really complicated technique, but this new device should be very useful in this field due to the easy way to perform this type of experiments. Absorbance in normal and parallel configuration has allowed us to study the $\mathrm{FcMeOH}$ redox behavior in the UVVis spectral region, obtaining more information about this redox couple scarcely used in spectroelectrochemistry. Normal configuration measurements are related to the global quantity of $\mathrm{FcMeOH}^{+}$generated, while parallel measurements also include information about the spatial distribution of the absorbent. The time-resolved evolution of the full spectra in the two optical configurations, normal and parallel, is needed in order to assess and check the molar absorption coefficient of $\mathrm{FcMeOH}^{+}$at any wavelength. This new methodology is an alternative to the more traditional approach to measure molar absorption coefficients that is based on long-optical path thin layer spectroelectrochemistry. By using small diameter optical fibers and slow enough scan rates, experiments can be performed generating an almost steady-state concentration of $\mathrm{FcMeOH}^{+}$in the solution closest to the electrode, achieving a maximum and constant absorbance value. This methodology clearly shows the importance and the advantages of an in-situ multi-response technique such as BSEC to obtain the molar absorption coefficients of electrogenerated redox species. A molar absorption coefficient of $8810 \pm 530 \mathrm{M}^{-1} \cdot \mathrm{cm}^{-1}$ at $282 \mathrm{~nm}$ has been experimentally obtained for $\mathrm{FcMeOH}^{+}$by using the $\mathrm{A}_{\mathrm{N}} / \mathrm{Q}$ ratio and without knowing either the optical path length 
or the $\mathrm{FcMeOH}$ concentration. This value has been validated in parallel configuration. This fact, which implies that $\mathrm{FcMeOH}$ can be used to validate not only electrochemical systems but also spectroelectrochemical set-ups, demonstrates another BSEC advantage. The novel SWCNTs-OTEs and the BSEC cell open new gates for studying complex chemical systems such as neurotransmitters, enzymes or DNA in order to shed more light on their reactions mechanisms. Our technical developments should be a significant advance in spectroelectrochemistry that could lead to new and interesting future applications because much more researchers will be able to use BSEC.

\section{ASSOCIATED CONTENT}

\section{Supporting Information}

Supplementary figures and information associated with this article. This material is available free of charge via the Internet at http://pubs.acs.org

\section{AUTHOR INFORMATION}

\section{Corresponding Author}

*E-mail: acolina@ubu.es.

Telephone number: +34 9472588 17. Fax: +34 947258831

\section{Author Contributions}

The manuscript was written through contributions of all authors. All authors have given approval to the final version of the manuscript.

\section{Notes}

The authors declare no competing financial interest.

\section{ACKNOWLEDGMENTS}

Support from Ministerio de Economía y Competitividad (CTQ2010-17127) and Junta de Castilla y León (GR71, BU349U13) is gratefully acknowledged. J. Garoz-Ruiz thanks Ministerio de Educación, Cultura y Deporte for his FPU fellowship. Barak D. B. Aaronson and Patrick R. Unwin are gratefully acknowledged for taking the FE-SEM images in the University of Warwick.

\section{REFERENCES}

(1) López-Palacios, J.; Colina, A.; Heras, A.; Ruiz, V.; Fuente, L. Anal. Chem. 2001, 73, 2883-2889.

(2) Ruiz, V.; Colina, Á.; Heras, A.; López-Palacios, J. Electrochim. Acta 2004, 50, 59-67.

(3) López-Palacios, J.; Heras, A.; Colina, Á.; Ruiz, V. Electrochim. Acta 2004, 49, 1027-1033.

(4) López-Palacios, J.; Muñoz, E.; Heras, M. A.; Colina, Á.; Ruiz, V. Electrochim. Acta 2006, 52, 234-239.

(5) Ventosa, E.; Colina, A.; Heras, A.; Martínez, A.; Orcajo, O.; Ruiz, V.; López-Palacios, J. Electrochim. Acta 2008, 53, 4219-4227.

(6) Ruiz, V.; Colina, Á.; Heras, A.; López-Palacios, J.; Seeber, R. Helv. Chim. Acta 2001, 84, 3628-3642.

(7) Ruiz, V.; Colina, Á.; Heras, A.; López-Palacios, J. Polym. Degrad. Stab. 2006, 91, 3117-3123.

(8) Ruiz, V.; Colina, Á.; Heras, A.; López-Palacios, J.; Seeber, R. Electrochem. Commun. 2002, 4, 451-456.

(9) Heras, A.; Colina, Á.; Ruiz, V.; López-Palacios, J. Electroanalysis 2003, 15, 702-708.
(10) Hu, L.; Hecht, D. S.; Grüner, G. Chem. Rev. 2010, 110, 57905844.

(11) Valcárcel, M.; Cárdenas, S.; Simonet, B. M. Anal. Chem. 2007, 79, 4788-4797.

(12) Agüí, L.; Yáñez-Sedeño, P.; Pingarrón, J. M. Anal. Chim. Acta 2008, 622, 11-47.

(13) Luo, H.; Shi, Z.; Li, N.; Gu, Z.; Zhuang, Q. Anal. Chem. 2001, $73,915-920$.

(14) Zhang, M.; Liu, K.; Xiang, L.; Lin, Y.; Su, L.; Mao, L. Anal. Chem. 2007, 79, 6559-6565.

(15) Tasis, D.; Tagmatarchis, N.; Bianco, A.; Prato, M. Chem. Rev. 2006, 106, 1105-1136.

(16) Sun, Y.-P.; Fu, K.; Lin, Y.; Huang, W. Acc. Chem. Res. 2002, 35, 1096-1104.

(17) Fu, L.; Yu, A. M. Rev. Adv. Mater. Sci. 2014, 36, 40-61.

(18) Cao, Q.; Rogers, J. A. Adv. Mater. 2009, 21, 29-53.

(19) Garoz-Ruiz, J.; Palmero, S.; Ibañez, D.; Heras, A.; Colina, A. Electrochem. Commun. 2012, 25, 1-4.

(20) Hecht, D. S.; Hu, L.; Irvin, G. Adv. Mater. 2011, 23, 14821513.

(21) Gruner, G. J. Mater. Chem. 2006, 16, 3533-3539.

(22) Zhang, D.; Ryu, K.; Liu, X.; Polikarpov, E.; Ly, J.; Tompson, M. E.; Zhou, C. Nano Lett. 2006, 6, 1880-1886.

(23) Feng, C.; Liu, K.; Wu, J.-S.; Liu, L.; Cheng, J.-S.; Zhang, Y.; Sun, Y.; Li, Q.; Fan, S.; Jiang, K. Adv. Funct. Mater. 2010, 20, 885891.

(24) Zou, Y.; Li, Q.; Liu, J.; Jin, Y.; Qian, Q.; Jiang, K.; Fan, S. Adv. Mater. 2013, 25, 6050-6056.

(25) Tseng, S. H.; Tai, N. H. Appl. Phys. Lett. 2009, 95, 204104, 1-

(26) Cole, M.; Hiralal, P.; Ying, K.; Li, C.; Zhang, Y.; Teo, K.; Ferrari, A.; Milne, W. J. Nanomater. 2012, 2012, 272960, 1-8.

(27) Wang, T.; Carlberg, B.; Jönsson, M.; Jeong, G.-H.; Campbell, E. E. B.; Liu, J. Appl. Phys. Lett. 2007, 91, 093123, 1-3.

(28) Ye, Y.; Mao, Y.; Wang, F.; Lu, H.; Qu, L.; Dai, L. J. Mater. Chem. 2011, 21, 837-842.

(29) Thanh, Q. N.; Jeong, H.; Kim, J.; Kevek, J. W.; Ahn, Y. H.; Lee, S.; Minot, E. D.; Park, J.-Y. Adv. Mater. 2012, 24, 4499-4504.

(30) Liu, H.; Takagi, D.; Chiashi, S.; Homma, Y. ACS Nano 2010, 4, 933-938.

(31) Wang, C.; Ryu, K.; de Arco, L. G.; Badmaev, A.; Zhang, J.; Lin, X.; Che, Y.; Zhou, C. Nano Res. 2010, 3, 831-842.

(32) Tabata, H.; Shimizu, M.; Ishibashi, K. Appl. Phys. Lett. 2009, $95,113107,1-3$

(33) Pint, C. L.; Xu, Y.-Q.; Moghazy, S.; Cherukuri, T.; Alvarez, N. T.; Haroz, E. H.; Mahzooni, S.; Doorn, S. K.; Kono, J.; Pasquali, M.; Hauge, R. H. ACS Nano 2010, 4, 1131-1145.

(34) $\mathrm{Wu}$, C. C.; Liu, C. H.; Zhong, Z. Nano Lett. 2010, 10, 10321036.

(35) In, J. B.; Lee, D.; Fornasiero, F.; Noy, A.; Grigoropoulos, C. P. ACS Nano 2012, 6, 7858-7866.

(36) Zhu, Y.; Lim, X.; Sim, M. C.; Lim, C. T.; Sow, C. H. Nanotechnology 2008, 19, 325304, 1-7.

(37) Fu, Y.; Qin, Y.; Wang, T.; Chen, S.; Liu, J. Adv. Mater. 2010, 22, 5039-5042.

(38) Abdelhalim, A.; Abdellah, A.; Scarpa, G.; Lugli, P. Carbon 2013, 61, 72-79.

(39) Wu, Z.; Chen, Z.; Du, X.; Logan, J. M.; Sippel, J.; Nikolou, M.; Kamaras, K.; Reynolds, J. R.; Tanner, D. B.; Hebard, A. F.; Rinzler, A. G. Science 2004, 305, 1273-1276.

(40) Hou, P.-X.; Yu, B.; Su, Y.; Shi, C.; Zhang, L.-L.; Liu, C.; Li, S.; Du, J.-H.; Cheng, H.-M. J. Mater. Chem. A 2014, 2, 1159-1164.

(41) Xu, G.-H.; Huang, J.-Q.; Zhang, Q.; Zhao, M.-Q.; Wei, F. Appl. Phys. A 2011, 103, 403-411.

(42) Lü, Q.; Cao, H.; Song, X.; Yan, H.; Gan, Z.; Liu, S. Chinese Sci. Bull. 2010, 55, 326-330.

(43) Woo, C.-S.; Lim, C.-H.; Cho, C.-W.; Park, B.; Ju, H.; Min, D.-H.; Lee, C.-J.; Lee, S.-B. Microelectron. Eng. 2007, 84, 16101613.

(44) Garoz-Ruiz, J.; Izquierdo, D.; Colina, A.; Palmero, S.; Heras, A. Anal. Bioanal. Chem. 2013, 405, 3593-3602. 
(45) Vilela, D.; Garoz, J.; Colina, Á.; González, M. C.; Escarpa, A. Anal. Chem. 2012, 84, 10838-10844.

(46) Flavel, B. S.; Yu, J.; Shapter, J. G.; Quinton, J. S. J. Mater. Chem. 2007, 17, 4757-4761.

(47) Zhu, Z.; Wang, M.; Gautam, A.; Nazor, J.; Momeu, C.; Prodanovic, R.; Schwaneberg, U. Biotechnol. J. 2007, 2, 241-248.

(48) Shan, D.; Yao, W.; Xue, H. Biosens. Bioelectron. 2007, 23, 432-437.

(49) Lertanantawong, B.; O’Mullane, A. P.; Zhang, J.; Surareungchai, W.; Somasundrum, M.; Bond, A. M. Anal. Chem. 2008, $80,6515-6525$.
(50) Vasilescu, I.; Eremia, S. A. V.; Radoi, A.; Radu, G.-L.; Litescu, S.-C. Anal. Methods 2013, 5, 2013-2019.

(51) Zhan, D.; Li, X.; Nepomnyashchii, A. B.; Alpuche-Aviles, M. A.; Fan, F.-R. F.; Bard, A. J. J. Electroanal. Chem. 2013, 688, 61-68.

(52) Allhusen, J. S.; Conboy, J. C. ACS Appl. Mater. Interfaces 2013, 5, 11683-11691.

(53) Weber, C. M.; Eisele, D. M.; Rabe, J. P.; Liang, Y.; Feng, X.; Zhi, L.; Müllen, K.; Lyon, J. L.; Williams, R.; Vanden Bout, D. A; Stevenson, K. J. Small 2010, 6, 184-189.

(54) Pruiksma, R.; McCreery, R. L. Anal. Chem. 1979, 51, 2253-

\section{Table of Contents}

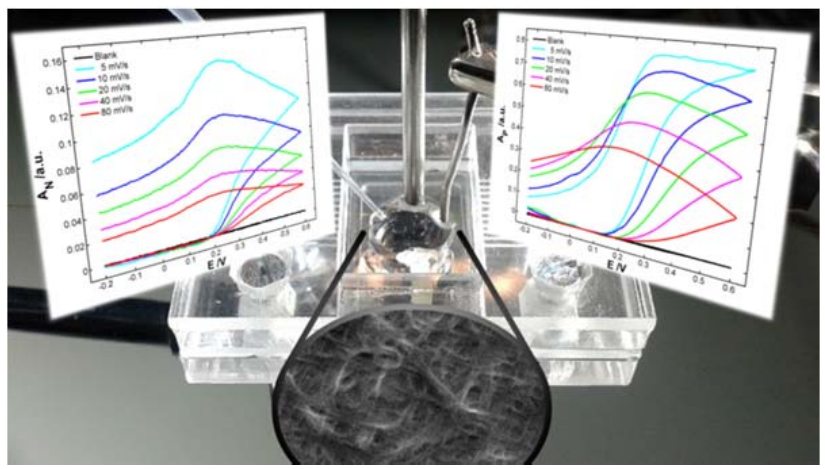

2257. 